\title{
A REALIZAÇÃO VARIÁVEL DE VIBRANTE SIMPLES EM LUGAR DE MÚLTIPLA NO PORTUGUÊS FALADO EM FLORES DA CUNHA (RS): MUDANÇAS SOCIAIS E LINGUÍSTICAS
}

\author{
Elisa Battisti* \\ Luisa Bitencourt Martins**
}

\begin{abstract}
RESUMO: O emprego de vibrante simples em lugar da múltipla no português brasileiro falado em Flores da Cunha (RS), traço resultante do contato com a fala dialetal italiana,foi submetido à análise de regra variável (LABOV, 1972, 1994, 2001, 2010). O emprego de vibrante simples regride na comunidade: os jovens são os que menos aplicam a regra. O estudo etnográfico (SPRADLEY, 1979) em Flores da Cunha revela que os jovens realizam práticas sociais inovadoras ao lado de práticas tradicionais. O emprego de vibrante simples em lugar da múltipla é valorado como local, embora seja relativamente desprestigiado
\end{abstract}

PALAVRAS-CHAVE: variação e mudança linguística; emprego de vibrante simples em lugar da múltipla; práticas sociais.

ABSTRACT: The variable rule analysis (LABOV, 1972, 1994, 2001, 2010) of the use of flap where a trill is expected in Brazilian Portuguese, in the speech community of Flores da Cunha (RS), showed that the use of flap is decreasing: young people are the ones who use less flap where a trill is expected. The ethnographic study (SPRADLEY, 1979) in Flores da Cunha reveals that young people engage in both innovative and traditional social practices. The use of flap where a trill is expected is valued as a local practice, but a relatively stigmatized one.

KEYWORDS: language variation and change; use of flap where a trill is expected; social practices

\section{INTRODUÇÃO}

Vibrante simples é a consoante que, no nível fonético, é produzida com uma leve batida da ponta da língua nos alvéolos, como na articulação do segmento medial de ir $a$. Vibrante múltipla também é produzida pela ponta da língua na região dos alvéolos, com mais de uma batida do articulador ativo (ponta da língua) no passivo (região alveolar) (erro).

\footnotetext{
* Universidade Federal do Rio Grande do Sul, Doutora em Letras e Pesquisadora do CNPq, battisti.elisa@gmail.com

** Universidade Federal do Rio Grande do Sul, graduanda em Letras e bolsista PIBIC/CNPq, bitencourtluisa@gmail.com
} 
A vibrante simples e a múltipla são fonemas no português, uma vez que há valor contrastivo entre esses segmentos, como se vê no par mínimo muro-murro. Dessas duas consoantes, apenas a vibrante múltipla realiza-se em diferentes fones: vibrante alveolar $[\mathrm{r}]$, fricativa velar $[\mathrm{X}]$ e fricativa glotal $[\mathrm{h}]$. Assim, murro, por exemplo, pode ser produzido como $m u[r] o, m u[X]$ o ou $m u[h] o$, sem que a diferente pronúncia implique mudança de significado.

O objeto deste estudo é um emprego inesperado em português, mas peculiar às comunidades brasileiras em que houve ou ainda há o contato do português com falares dialetais de imigrantes (italianos, alemães, entre outros) e seus descendentes: o emprego variável da vibrante simples em lugar da múltipla, como em parreira pareira, carro caro. Esse emprego se verifica em, por exemplo, Flores da Cunha, pequeno município brasileiro fundado por imigrantes italianos no final do século XIX, localizado ao sul do Brasil, no nordeste do estado do Rio Grande do Sul. Nele, há contato entre português e fala dialetal italiana.

O objetivo deste artigo é apresentar e discutir resultados da análise de regra variável (LABOV, 1972, 1994, 2001, 2010) do emprego de vibrante simples em lugar da múltipla no português falado em Flores da Cunha (RS), tanto em posição intervocálica (murro) quanto em início de palavra ( $\underline{r} u a)$. Para a Teoria da Variação laboviana, qualquer realização variável é condicionada tanto linguística quanto extralinguisticamente (ou socialmente). São exemplos de condicionadores linguísticos o contato entre sons, a maior ou menor tonicidade das sílabas, e de condicionadores sociais, a idade, procedência geográfica, ocupação, grau de escolarização, entre outras características dos usuários da língua. Além disso, a variação é concebida nesse modelo como uma etapa no processo de mudança linguística. Por isso, a análise de regra variável, de natureza quantitativa, verifica não só os condicionadores estruturais e sociais de um processo, mas também sua tendência a avançar na comunidade, regredir, ou manter-se estável. É o que se faz numa das partes do trabalho (seção Resultados, Análise de Regra Variável).

$\mathrm{Na}$ outra parte do trabalho (seção Resultados, Estudo Etnográfico), os resultados parciais do estudo etnográfico (SPRADLEY, 1979) que vem sendo realizado em Flores da Cunha viabilizam discutir e interpretar os resultados estatísticos da análise de regra variável no viés das práticas sociais (ECKERT, 2000). A crença básica dessa linha de investigação é a de que a fala é uma das ações que realizamos, diariamente, na vida em sociedade. As formas alternantes que eventualmente delas se originam adquirem valor social nos diferentes grupos de usuários da língua, relativamente à identidade dos sujeitos falantes e ao quadro de expectativas dos diferentes campos sobre comportamentos e trocas sociais viabilizadas pela fala (BOURDIEU, 2008). Assim, valores sociais das alternantes não são dados, não existem a priori. Emergem das práticas de grupo, por isso a necessidade de realizar estudo etnográfico.

O interesse em realizar esta investigação vem da constatação de que, passados mais de cento e trinta anos da imigração, levando-se em conta que dentro desse período 
houve a proibição da fala de idiomas estrangeiros em público no Brasil ${ }^{1}$, o emprego da vibrante simples em lugar da múltipla ainda é frequente no português falado em Flores da Cunha. É uma realização saliente aos próprios florenses, que ora afirmam ser 'erado' falar assim, ora imitam quem fale dessa forma, ora empregam a vibrante simples entre si, aparentemente sem se darem conta, ora corrigem sua fala quando em interação com falantes de fora da comunidade. Vêm daí as questões norteadoras do trabalho: qual é a frequência total do emprego de vibrante simples em lugar da múltipla na comunidade? O que condiciona o emprego, em termos sociais e linguísticos? Tende a progredir, regredir ou manter-se estável? Que valores sociais associam-se à variante?

Iniciamos o artigo com uma revisão de literatura, para, na seção seguinte, apresentar a metodologia e, depois, os resultados da análise de regra variável do emprego de vibrante simples em lugar da múltipla no português falado em Flores da Cunha. Por fim, abordamos alguns achados do estudo etnográfico em realização, para discorrer sobre práticas e valores sociais das alternantes e, assim, buscar explicação para os padrões de avanço ou regressão do processo variável na comunidade.

\section{REVISÃO DE LITERATURA}

Frosi e Mioranza (1983), estudando o contato dos falares dialetais italianos com o português na antiga região colonial italiana do Rio Grande do Sul (RCI-RS), registram a frequente realização da vibrante simples em lugar da múltipla no português. Esse seria um dos traços característicos da fala bilíngue, distinto do falar monolíngue português. Os autores afirmam que o italiano standard possui a vibrante múltipla, mas os dialetos falados no norte da Itália, região de origem de grande parte dos imigrantes italianos vindos ao Brasil, não possuem. Decorre daí o emprego de vibrante simples em lugar da múltipla no português, pela transferência de uma característica da fala dialetal italiana. Frosi e Mioranza (1983, p.352) explicam: "Tratando-se de palavras cuja forma é semelhante nos dois sistemas linguísticos [...] o desvio de uma norma estrutural de lingua portuguesa estabelece uma sequência fônica mais própria do sistema dialetal italiano."

Rossi (2000) investigou o emprego de vibrante simples em lugar da múltipla no português falado em Chapecó (SC) e Flores da Cunha (RS), em dados de entrevistas sociolinguísticas do VARSUL (Variação Linguística Urbana da Região Sul, UFPR, UFSC, UFRGS, PUCRS) ${ }^{2}$. A autora efetuou análise de regra variável desse emprego

\footnotetext{
${ }^{1}$ Em 1939, com parte da Campanha de Nacionalização do Estado Novo brasileiro (1937-1945), proibiu-se a fala de idiomas estrangeiros em público. A Campanha buscava estabelecer um ideal nacional e assim centralizar o poder, para o que a eliminação de regionalismos era necessária (PESAVENTO, 1984). A integração das comunidades de imigrantes à população brasileira pela exigência de que falassem apenas português contribuiria para alcançar o nacionalismo desejado.

${ }^{2}$ O projeto VARSUL (Variação Linguística na Região Sul do Brasil) tem por objetivo geral a descrição do português falado e escrito de áreas socioculturalmente representativas do Sul do Brasil. Constituem seu acervo o Banco de Dados VARSUL, a Amostra Digital VARSUL e o Banco de Dados Diacrônico. Disponível em: http://www.varsul.org.br/. Acesso em 8 de fevereiro de 2012.
} 
apenas em posição intervocálica, submetendo-os a tratamento estatístico através do Programa VARBRUL 2S $1^{3}$. Obteve os dados de entrevistas de trinta e dois informantes, dezesseis de cada uma das comunidades pesquisadas. Os informantes foram selecionados de acordo com a idade (25 a 50 anos, mais de 50 anos), o sexo (masculino e feminino) e a escolaridade (primário, colegial). Levou em conta cinco variáveis linguísticas (contexto fonológico anterior, contexto fonológico posterior, tonicidade da sílaba, número de sílabas e classe da palavra). O total de dados analisados foi de 1044. A vibrante simples realizou-se em $46 \%$ desse total de dados dados, mas foi $45 \%$ sua realização em Chapecó, e $52 \%$ sua realização em Flores da Cunha. Os resultados estatísticos apontaram uma forte influência dos fatores sociais sobre $\mathrm{o}$ processo investigado. Cruzamentos revelaram uma tendência de as mulheres, independentemente da comunidade, da idade ou da escolaridade, privilegiaram o emprego da vibrante múltipla. Os informantes da faixa etária de 25 a 50 anos realizaram mais a vibrante múltipla do que aqueles com mais de 50 anos. Isso sugere à autora que uma mudança linguística esteja em curso nas comunidades, rumo à minimização do emprego de vibrante simples em lugar da múltipla. Isso pode ser potencializado, segundo a autora, pela escolarização, já que os informantes com mais escolaridade também privilegiaram mais o uso da múltipla. Quanto ao número de sílabas, única variável linguística selecionada pelo VARBRUL, os resultados apontaram as palavras polissilábicas como favorecedoras da múltipla, as dissilábicas como favorecedoras da simples.

Spessatto (2003) investigou as produções de vibrante múltipla e simples apenas em Chapecó (SC), também com dados de entrevistas do VARSUL, num total de vinte e quatro entrevistas. Distinguiu falantes bilíngues de monolíngues, homens de mulheres, falantes de escolaridade primária, ginasial e colegial, e subdividiu-os em três grupos etários: 25 a 39 anos, 40 a 55 anos, acima de 55 anos. Levantou 3217 dados, mas apenas a análise de 1949 desses dados interessa ao presente estudo porque são contextos de vibrante múltipla. Tanto a posição intervocálica quanto a inicial de palavra foram consideradas pela autora. Realizada a análise de regra variável com os programas do pacote VARBRUL, constatou $46 \%$ de emprego de vibrante simples em lugar de múltipla, praticamente a mesma taxa encontrada por Rossi (2000) para Chapecó. As variáveis sociais foram apontadas pelo pacote de programas VARBRUL como as mais relevantes para o condicionamento do fenômeno, na seguinte ordem: escolaridade, idade, bilinguismo e sexo. São os informantes de menor escolaridade (primária) os que favorecem o emprego de vibrante simples em lugar da múltipla, como também os de mais idade (acima de 55 anos), os bilíngues e os de sexo masculino. Esses resultados conformam-se aos de Rossi (2000), principalmente os que dizem respeito à idade e sexo. A única variável linguística selecionada pelo VARBRUL foi posição do fonema na palavra, sendo a inicial a que privilegia o emprego da vibrante múltipla.

Bovo (2004) estudou a fala em língua portuguesa de bilíngues português-italiano da zona rural de Caxias do Sul em dados de vinte e quatro entrevistas do BDSer (Banco de Dados de Fala da Serra Gaúcha, UCS). Analisou a realização variável da vibrante

\footnotetext{
${ }^{3}$ Os programas computacionais do pacote VARBRUL realizam análise estatística de regressão logística.
}

Cadernos do IL. Porto Alegre, n. ${ }^{\circ}$ 42, junho de 2011. p. 146-158. 
simples, que ela chamou de tepe, em contextos em que se espera vibrante (múltipla) em onset silábico (aroz, carroça). Distinguiu os informantes por gênero (masculino e feminino), escolaridade (Primário, Fundamental, Médio/Superior), bilinguismo (ativo, passivo, nulo), idade (15 a 25 anos, 26 a 49 anos, 50 ou mais anos). Controlou a posição da sílaba na palavra (inicial, medial), o número de sílabas na palavra (monossílabo, dissílabo, trissílabo, polissílabo) e a tonicidade da sílaba (átona, tônica). Foram 1461 os contextos analisados, e a frequência total de emprego de tepe em lugar de vibrante foi de 44\%, índice próximo aos verificados por Rossi (2000) e Spessatto (2003) em Chapecó e em Flores da Cunha. Em todas as rodadas da análise quantitativa, as variáveis sociais foram sempre selecionadas, as linguísticas, exceto uma (posição da sílaba na palavra), descartadas pelo pacote de programas VARBRUL. Dentre os fatores de variáveis sociais, condicionam favoravelmente a realização de tepe em lugar de vibrante o nível primário de escolaridade $\left(1^{\mathrm{a}}\right.$ a $4^{\mathrm{a}}$ série), o status do falante como bilíngue, quer ativo, quer passivo, a idade de 50 ou mais anos e o gênero masculino; e dos fatores da variável posição da sílaba na palavra, a posição medial é condicionadora. Esses resultados estão de acordo com os de Rossi (2000) e os de Spessatto (2003).

Além da análise de regra variável, Bovo (2004) efetuou estudo etnográfico sobre gênero na comunidade de prática Clube de Mães de uma localidade da zona rural de Caxias do Sul onde as entrevistas sociolinguísticas haviam sido realizadas. O estudo revela que, apesar do sistema patriarcal e dos valores machistas da localidade, as mulheres preferem viver 'na colônia' a viver na cidade. É prática feminina local orientarse à cidade quando em jogo estão oportunidades de ascensão social e crescimento profissional. Fora isso, pode-se dizer que as mulheres orientam-se ao local, à própria comunidade rural em que habitam. Há uma motivação para isso: a terra é herdada pelos homens (as mulheres têm acesso a ela apenas pelo casamento). Assim, as filhas de todas as famílias são estimuladas a estudar e arranjar emprego na cidade (e falar o português padrão), para garantia da sobrevivência futura. Já aos meninos, desde cedo, passam-se em italiano as instruções sobre o manejo da terra e dos animais. Poucos são estimulados a prosseguir estudando além do nível Médio. Assim, ser mulher nessa localidade é realizar práticas sociais distintas, orientadas à cidade e com emprego de portuguêspadrão, de um lado, e, de outro, à comunidade e à família, o que explica empregarem um pouco mais de vibrante múltipla do que os homens.

A revisão de literatura efetuada mostra que predominam as variáveis sociais no condicionamento do processo variável em questão, por isso a importância de controlálas. A frequência total de aplicação vai de $40 \%$ a $50 \%$, e ao menos uma variável linguística tem papel. Esses resultados relacionam-se a práticas sociais locais, que seguem dando espaço à fala bilíngue e, assim, à transferência de traços da fala dialetal italiana para o português. Todo esse conjunto de resultados foi o que consideramos para conceber e para realizar o estudo do emprego de vibrante simples em lugar da múltipla em Flores da Cunha, em dados do BDSer, como será exposto a seguir.

\section{METODOLOGIA}

Cadernos do IL. Porto Alegre, n. ${ }^{\circ}$ 42, junho de 2011. p. 146-158. 
A comunidade de fala do presente estudo é, como se esclareceu na Introdução, Flores da Cunha (RS). Flores da Cunha situa-se na RCI-RS. Tem uma população pequena (em torno de 27.000 habitantes $^{4}$ ), mas não em redução; e celebra suas origens italianas em festivais e movimentos culturais. É município vizinho a Caxias do Sul, maior cidade do Rio Grande do Sul após a capital, Porto Alegre. Na área de 272,66 km², a zona rural é relativamente grande e o pequeno centro urbano dá sinais de crescimento. Sua economia é diversificada, inclui indústria, comércio, serviços, agricultura. O município é um dos maiores produtores de vinho do Brasil e sua indústria moveleira exporta para a América Latina, Estados Unidos e Europa, principalmente.

\section{ANÁLISE DE REGRA VARIÁVEL}

Para a análise de regra variável, utilizaram-se trinta e duas entrevistas sociolinguísticas do BDSer de Flores da Cunha de que foram levantados os contextos de vibrante. Essas entrevistas foram realizadas entre 2008 e 2009. Os informantes são dos dois gêneros, da zona urbana e rural e pertencem a quatro grupos etários: 18 a 30 anos de idade; 31 a 50 anos; 51 a 70 anos; 71 ou mais anos. Tais características configuram as três variáveis extralinguísticas controladas na análise: Gênero, Local de Residência e Idade. Considerando o que se constatou nos estudos revisados (seção acima), nossas hipóteses foram as de que falantes do gênero masculino, idosos e de zona rural seriam os condicionadores da aplicação da regra.

As variáveis linguísticas controladas são: Posição da Sílaba na Palavra, Número de Sílabas da Palavra, Tonicidade da Sílaba. A hipótese foi a de que a posição medial, monossílabos e sílabas átonas condicionariam o emprego de vibrante simples em lugar da múltipla. Os 2151 contextos levantados das entrevistas sociolinguísticas foram codificados e posteriormente submetidos aos programas computacionais do pacote VARBRUL, versão Goldvarb $\mathrm{X}^{5}$ para ambiente Windows, que realizam análise estatística de regressão logística. O Quadro 1 traz o conjunto de variáveis controladas na análise, com exemplos.

Quadro 1 - Variáveis controladas e exemplos

\begin{tabular}{|l|l|}
\hline \multicolumn{1}{|c|}{ Variáveis linguísticas } & Variáveis extralinguísticas \\
\hline Tonicidade da sílaba & Gênero \\
Pretônica: raposa, carregado & Feminino \\
Tônica: rato, carroça & Masculino \\
Postônica: terra, farra & \\
\hline
\end{tabular}

\footnotetext{
${ }^{4}$ Cf. dados do IBGE, censo 2010. Disponíveis em www.ibge.gov.br. Acesso em 13 de março de 2011.

${ }^{5}$ Disponível em: http://individual.utoronto.ca/tagliamonte/goldvarb.htm . Acesso em 21 de dezembro de 2010 .
} 


\begin{tabular}{|l|c|}
\hline Posição da sílaba na palavra & Idade \\
Inicial: rua, relógio & 18 a 29 anos \\
Medial: arranhão, correio & 30 a 49 anos \\
Final: cachorro, guerra & 50 a 69 anos \\
& 70 ou mais anos \\
\hline Número de sílabas da palavra & Local de residência \\
Monossílabo: rã, rol & Zona urbana \\
Dissílabo: rua, corre & Zona rural \\
Trissílabo: romeiro, rápido & \\
Polissílabo: correria, rabanete & \\
\hline & Grau de escolaridade \\
& Primário \\
& Fundamental \\
& Médio e Superior \\
\hline
\end{tabular}

Os valores obtidos na análise quantitativa são expressos em percentuais e em pesos relativos. Os percentuais expressam a distribuição dos dados e realizações variáveis por fator considerado nas diferentes variáveis controladas. Os pesos relativos expressam a tendência de o processo estudado ocorrer, como efeito dos diferentes fatores considerados na análise. Esses últimos estão compreendidos no intervalo de 0 a 1: valores em torno de 0,5 indicam a neutralidade do fator em relação ao processo estudado, valores abaixo de 0,5 indicam que o fator não condiciona (desfavorece) 0 processo, valores acima de 0,5 indicam que o fator condiciona (favorece) o processo.

\section{ESTUDO ETNOGRÁFICO}

O estudo etnográfico que estamos realizando em Flores da Cunha tem o objetivo de viabilizar o estudo da cultura local pela inferenciação, como forma de verificar e compreender mudanças sociais ligadas a mudanças linguísticas. Tal inferenciação, conforme Spradley (1979), é um processo de aprendizagem realizada pelo pesquisador no convívio com as pessoas, com os grupos pesquisados. São três as grandes fontes de inferências: o que as pessoas dizem, o que elas fazem (suas práticas sociais) e os artefatos que elas usam.

Os resultados que apresentaremos são ainda parte desse estudo. Alguns são dados gerados das entrevistas sociolinguísticas de que se levantaram os contextos de vibrante considerados antes na análise de regra variável. Voltam-se ao que as pessoas dizem, aos assuntos de que falam, reveladores não só das razões tácitas para inovações, inclusive linguísticas, como também de visões de mundo motivadoras de mudanças ou de resistência a elas. Levantamos das entrevistas afirmações das pessoas sobre o que elas fazem diariamente, afirmações ligadas às dimensões do trabalho, família, lazer, estudos, religião, política e à própria comunidade.

Outros são dados gerados de momentos de observação participante em festas de capela com almoços ou jantares, feiras, celebrações religiosas como a de Corpus Christi, em que se procurou fazer o que os outros fazem. Assim, observaram-se as ações 
das pessoas, o protocolo seguido na realização dessas ações, vestimentas, artefatos utilizados.

\section{RESULTADOS}

\section{ANÁLISE DE REGRA VARIÁVEL}

As tabelas de 1 a 4 trazem os resultados das variáveis Local de Residência, Idade, Gênero e Posição da Sílaba na Palavra, na ordem de seleção estabelecida pelo pacote de programas VARBRUL. Percebe-se que o emprego de vibrante simples em lugar da múltipla em Flores da Cunha (RS) é condicionado predominantemente por variáveis sociais, confirmando que Rossi (2000), Spessatto (2003) e Bovo (2004) verificaram em Chapecó, Flores da Cunha e Caxias do Sul.

Tabela 1 - Local de Residência

\begin{tabular}{c|c|c|c}
\hline Fatores & Aplicação/Total & $\mathbf{\%}$ & Peso Relativo \\
\hline Zona urbana & $398 / 1153$ & 34 & 0,34 \\
\hline Zona rural & $606 / 998$ & 61 & 0,67 \\
\hline TOTAL & $1004 / 2151$ & 46 & \\
\hline
\end{tabular}

Input: 0,46

Significância: 0,09

O fator Zona Rural favorece a aplicação da regra. Já o papel do fator Zona Urbana é desfavorecedor. Uma das razões pode estar no fato de, na zona rural, a fala bilíngue português-dialeto italiano ainda ser prática social corrente nas conversas entre familiares, vizinhos e amigos, que pudemos constatar em festas de capela e nas propriedades rurais, principalmente entre os mais velhos.

Tabela 2 - Idade

\begin{tabular}{c|c|c|c}
\hline Fatores & Aplicação/Total & $\mathbf{\%}$ & Peso Relativo \\
\hline 18 a 30 anos & $208 / 614$ & 34 & 0,31 \\
\hline 31 a 50 anos & $209 / 519$ & 40 & 0,43 \\
\hline 51 a 70 anos & $247 / 520$ & 47 & 0,56 \\
\hline 71 ou mais anos & $340 / 498$ & 68 & 0,73 \\
\hline TOTAL & $1004 / 2151$ & 46 & \multicolumn{3}{|c}{ Significância: 0,09}
\end{tabular}

Os fatores 18 a 30 anos e 31 a 50 anos desfavorecem o emprego de vibrante simples em lugar da múltipla, os fatores 51 a 70 anos e 71 ou mais anos favorecem a aplicação da regra. O decréscimo gradual verificado do grupo etário mais velho para o mais jovem é clara indicação da tendência de regressão do processo em Flores da Cunha, tendência explicada pelas práticas sociais diárias dos jovens florenses, 
abordadas na seção seguinte. Essa tendência à regressão da regra está de acordo com o verificado por Rossi (2000).

Tabela 3 - Gênero

\begin{tabular}{c|c|c|c}
\hline Fatores & Aplicação/Total & \% & Peso Relativo \\
\hline Masculino & $562 / 1145$ & 49 & 0,52 \\
\hline Feminino & $442 / 1006$ & 44 & 0,46 \\
\hline TOTAL & $1004 / 2151$ & 46 & \multicolumn{3}{|c}{ Significância: 0,09}
\end{tabular}

Os valores dos fatores Masculino e Feminino, em torno do ponto neutro, não permitem atribuir um papel claro à variável Gênero no emprego de vibrante simples em lugar da múltipla em Flores da Cunha. Mas a maior proporção de aplicação pelos homens sugere que o emprego da vibrante simples possa estar mais ligado à identidade masculina na comunidade, e se conforma aos resultados obtidos por Rossi (2000), Spessatto (2003) e Bovo (2004).

Tabela 4 - Posição da sílaba na palavra

\begin{tabular}{c|c|c|c}
\hline Fatores & Aplicação/Total & \% & Peso Relativo \\
\hline Medial (parreira) & $273 / 548$ & 50 & 0,53 \\
\hline Inicial (rua) & $615 / 1324$ & 46 & 0,49 \\
\hline Final (guerra) & $116 / 279$ & 42 & 0,45 \\
\hline TOTAL & $1004 / 2151$ & 46 & \multicolumn{4}{|c}{ Significância: 0,09}
\end{tabular}

Única variável linguística selecionada pelo VARBRUL, Posição da Sílaba na Palavra tem fatores com resultados em torno de 0,5 , portanto com papel neutro frente ao processo. No entanto, o fator Medial é o único com valor acima de 0,5 , em oposição aos outros dois fatores, o que autoriza a afirmar o predomínio do emprego de vibrante simples em posições que não coincidam com as bordas da palavra. Essa interpretação está de acordo com o verificado por Spessatto (2003) e Bovo (2004).

Em termos sociais, nossos resultados de Flores da Cunha para essas quatro variáveis sugerem que o emprego de vibrante simples em lugar de múltipla seja um fenômeno rural, promovido pelos falantes mais velhos. O emprego de vibrante múltipla como se espera em português, um fenômeno urbano promovido pelos mais jovens. Estamos, portanto, diante de variação linguística na mudança em progresso, mudança que deve estar acompanhando transformações sociais. O que as práticas sociais dos jovens revelam sobre essas transformações?

\section{ESTUDO ETNOGRÁFICO}


À primeira vista, os jovens de Flores da Cunha não diferem de qualquer outro jovem brasileiro. Considerando o estado do Rio Grande do Sul e em termos de vestimentas, por exemplo, assemelham-se à maioria dos jovens gaúchos. Mas a observação mais sistemática de suas práticas sociais e a consideração aos assuntos de que falam e às questões sobre que debatem revelam um localismo peculiar. Esse localismo em parte explica as vinculações de suas práticas com as tradições da imigração italiana, noutra parte, a necessidade/desejo de inovar e rever essas vinculações.

Talvez reforçada pelas festas locais e pelo turismo, que celebra e comercializa as raízes italianas, há uma consciência étnica que serve de explicação, para o próprio jovem, da razão de realizar certas práticas, como se pode captar de uma afirmação assim:

(...) a maioria (dos jovens) aqui da cidade tem descendência italiana. (Tu) sabe que descendência italiana sempre tem a matriarca e o patriarca. Eu acho que a maioria sai, assim, bastante "família" e sempre tem que jantar junto com o pai e com a mãe, salvo exceções. (...) Chega essa idade assim e "ah, tenho que casar, tenho que ter minha família". (M. de O., 24 anos, masculino, zona urbana)

A vida em família não parece ser algo que o jovem gostaria de evitar, tampouco um real desejo seu, mas algo que acontece com ele. O jovem florense nem se rebela contra a família, nem adere incondicionalmente a ela, o que pode estar na base das graduais e pequenas mudanças diárias por ele promovidas, embora as tradições sejam seguidas, inclusive nos momentos de lazer:

Aqui (se) segue...um pouco de tradição da cidade, que no caso é, no domingo, sair e dar voltas ao redor da praça. É uma coisa que a cidade pequena tem. Ficar parado olhando o movimento passar. (M. de O., 24 anos, masculino, zona urbana)

Essa fala não revela propriamente uma opção do jovem, mas uma consequência das tradições e, mais importante, do fato de a cidade não oferecer opções de lazer como teatro, cinema, shopping center, comentário que soa como queixa na fala de muitos deles, e que é razão para buscarem, em outras cidades, diferentes formas de distração:

Eu gostaria de viver em Caxias... Acho que desde pequena... uma vez eu fui na Festa da Uva lá e nossa! ... sempre gostei de Caxias, tanto pequena quanto adolescente, sempre quis ir pra Caxias, mas minha mãe não deixava e, nossa... eu ia no cinema, ficava feliz, sempre gostei da cidade (C. S., 18 anos, feminino, zona urbana)

Deslocar-se a outras localidades, dessa forma, parece fazer parte de ser jovem em Flores da Cunha, inclusive para cursar faculdade (não há instituição de Ensino Superior em Flores da Cunha), mas em um roteiro de ida e volta: o jovem realiza práticas fora da comunidade e retorna a Flores da Cunha. Em termos linguísticos, tem contato com outros padrões de fala e pode, nessa circunstância, sentir-se pressionado a evitar formas reveladoras de sua identidade local, como empregar vibrante simples. É

Cadernos do IL. Porto Alegre, n. ${ }^{\circ}$ 42, junho de 2011. p. 146-158. 
possível então que, buscando sintonia com a fala do outro, abra mão momentaneamente de marcas locais, principalmente daquela tratada no presente estudo, bastante saliente para alguns usuários da língua. Depois, esse mesmo jovem retorna a Flores da Cunha e, lá, volta a orientar-se pela identidade e valores locais, embora não realize práticas sociais exatamente da mesma forma que os florenses mais velhos. Sobre sair da comunidade e retornar a ela, e também sobre mudanças geracionais, observe-se a afirmação de outra jovem sobre trabalho:

A gurizada daqui não quer mais trabalhar na colônia. (...) Vão pra Caxias estudar. Todos fazem faculdade, a grande maioria. Aí, então, ninguém mais quer trabalhar na colônia como acontecia antigamente, as famílias eram numerosas, as pessoas ficavam na colônia e não estudavam, né. (...) Eu acho que mais pessoas continuam morando aqui e vão e voltam, do que se mudam. São poucos que se mudam. (C. M., 23 anos, zona rural)

A jovem começa afirmando que os jovens não querem mais trabalhar na terra, nas propriedades rurais, junto à família. A suposição imediata seria a de que eles desejariam migrar para a cidade, mas não é o que vai na última afirmação da jovem, repetida a seguir: "Eu acho que mais pessoas continuam morando aqui e vão e voltam, do que se mudam. São poucos que se mudam." É o tipo de trabalho o que jovens de zona rural criticam: muito duro, segundo alguns. Mas não criticam o lugar onde moram, que não abandonam, se possível. É o que observamos em campo. Nas propriedades rurais onde se cultiva uva, por exemplo - setor bastante lucrativo para os pequenos proprietários rurais da região -, jovens que, na adolescência, planejaram abandonar a zona rural afirmam ter se dado conta, alguns anos depois, de que a viticultura lhes daria um retorno financeiro interessante. E de fato trabalham na terra, acompanhando seus pais.

Sobre práticas linguísticas, em específico, são raras as afirmações a respeito nas entrevistas sociolinguísticas, como é de se esperar. Mas veja-se uma interessante, de uma jovem que falava sobre padrões familiares:

Assim: começa sempre pelos avós, então, a criação dos meus tios, né, era uma e veio vindo ... e a gente sempre pegava (...) o próprio falar: tu fala "erado", e quem convive contigo que fala "erado" vai falar sempre "erado". (C. P., 18 anos, feminino, zona urbana)

A jovem tem ciência de que, ao falarmos, tendemos a reproduzir práticas linguísticas. $\mathrm{O}$ interessante é que ela seleciona justamente o objeto de nosso estudo como exemplo. Isso mostra não só que a alternante é saliente para muitos florenses, como deixa transparecer que algo de negativo a acompanha. A jovem entende o emprego de vibrante simples como um erro que se poderia/deveria evitar. Essa afirmação revela, em nosso entender, uma das motivações para os mais jovens estarem, gradualmente, substituindo o emprego de vibrante simples por múltipla no português de Flores da Cunha, por que essa variante parece desprestigiada pelos próprios florenses, embora emerja com bastante naturalidade na fala de alguns.

Em Flores da Cunha, as práticas religiosas, quase exclusivamente católicas, têm relevo. Embora, nas entrevistas sociolinguísticas, esse tópico não tenha rendido uma boa 
conversa, temos observado o envolvimento de jovens em práticas religiosas, principalmente as festivas. Na celebração de Corpus Christi, por exemplo, que envolve uma missa na igreja matriz e, em seguida, a procissão do Senhor Morto sobre tapetes de serragem, constatamos a presença de número significativo de jovens. Não pareciam estar lá forçados, pelo contrário, sua participação demonstrou-se fervorosa. Constatamos também que muitos tapetes haviam sido confeccionados por grupos de jovens juventude católica, escoteiros, organizações antidrogas, grêmios desportivos.

Percebemos nos jovens florenses os jeans, tênis, jaquetas, bonés e celulares que acompanhariam os jovens em qualquer outro lugar do Rio Grande do Sul. Um pouco mais cuidados e 'arrumadinhos', é verdade, mas todos esses itens estavam lá, no visual dos jovens, numa demonstração de que a prática é local, mas os artefatos são supralocais.

Em termos de práticas sociais e cultura local, então, vemos no estudo etnográfico em andamento indícios de um hibridismo em que aspectos tradicionais e inovadores convivem, em que mudanças linguísticas (entre outras) ocorrem, mesmo que lentamente, acompanhando mudanças sociais.

\section{CONCLUSÃO}

Realizamos análise de regra variável do emprego de vibrante simples em lugar da múltipla no português falado em Flores da Cunha (RS), processo esse que produz uma forma saliente aos usuários da língua: diferentemente da maioria das variantes fonético-fonológicas, que passam despercebidas aos próprios falantes, promotores da variação, o emprego de vibrante simples em lugar da múltipla dá origem a variantes percebidas pelos florenses em sua fala e na dos outros, e valoradas conforme suas práticas sociais locais. Talvez por isso o condicionamento social tenha se mostrado tão expressivo.

O emprego de vibrante simples está em regressão no português falado em Flores da Cunha. Aos poucos, o falar local vai se conformando ao que se espera de uma variedade monolíngue-português. A realização da vibrante simples é condicionada por idosos do gênero masculino e habitantes da zona rural, como também pela posição medial de palavra.

Cumpridas algumas etapas do estudo etnográfico na comunidade, pudemos observar, no que se refere às práticas sociais dos jovens, que mudanças sociais ocorrem na comunidade, o que se relaciona às mudanças linguísticas verificadas. Os jovens florenses reproduzem em parte as práticas sociais tradicionais, mas se abrem a inovações. Têm na cidade poucas opções de estudo e lazer, o que os faz deslocarem-se diariamente a outras localidades para frequentarem faculdade e se divertirem, mas seguem morando nela, acabam retornando a Flores da Cunha. Observações como essas nos permitem interpretar os resultados da análise quantitativa e confirmar a tendência de mudança fonológica no português em Flores da Cunha, a ser concretizada pelas gerações futuras. 


\section{REFERÊNCIAS}

BOURDIEU, P. A economia das trocas linguísticas: O que falar quer dizer. 2.ed. São Paulo: EDUSP, 2008.

BOVO, Nínive Magdiel Peter. A variação da vibrante e o seu valor social. Caxias do Sul: UCS. 2004. Dissertação (Mestrado em Letras e Cultura Regional), Programa de Pós-Graduação em Letras e Cultura Regional, Universidade de Caxias do Sul ECKERT, P. Linguistic variation as social practice. Malden/Oxford: Blackwell, 2000.

FROSI, V. M.; MIORANZA, C. Dialetos italianos: um perfil linguístico dos ítalobrasileiros do nordeste do Rio Grande do Sul. Caxias do Sul: EDUCS, 1983.

LABOV, W. Sociolinguistic patterns. Philadelphia: University of Philadelphia Press, 1972. 1994. . Principles of linguistic change - internal factors. Malden/Oxford: Blackwell, 2001 . Principles of linguistic change - social factors. Malden/Oxford: Blackwell, - Principles of linguistic change - cognitive and cultural factors. Malden/Oxford: Wiley-Blackwell, 2010.

PESAVENTO, S.J. História do Rio Grande do Sul. 3.ed. Porto Alegre: Mercado Aberto, 1984.

ROSSI, A. A variação da vibrante múltipla no interior da palavra lexical na fala de descendentes italianos das cidades sulinas Chapecó/SC e Flores da Cunha /RS. Working papers em linguística, UFSC, n.4, p.54-69, 2000.

SPESSATTO, M.B. Linguagem e colonização. Chapecó: Argos, 2003.

SPRADLEY, J.P. The ethnographic interview. New York: Holt, Rinehart and Winston, 1979. 